\title{
P3HT:PCBM blend films phase diagram on the base of variable-temperature spectroscopic ellipsometry
}

\author{
Barbara Hajduk*, Henryk Bednarski, Bożena Jarząbek, Henryk Janeczek \\ and Paweł Nitschke
}

\author{
Full Research Paper \\ Address: \\ Centre of Polymer and Carbon Materials, Polish Academy of \\ Sciences, 34 Marie Curie-Skłodowska str., 41-819 Zabrze, Poland \\ Email: \\ Barbara Hajduk ${ }^{*}$ - bhajduk@cmpw-pan.edu.pl \\ * Corresponding author \\ Keywords: \\ non-linear optics; organic semiconductors; spectroscopic ellipsometry; \\ theoretical modeling; thin films
}

Beilstein J. Nanotechnol. 2018, 9, 1108-1115.

doi:10.3762/bjnano.9.102

Received: 23 June 2017

Accepted: 16 March 2018

Published: 05 April 2018

Associate Editor: A. Gölzhäuser

(C) 2018 Hajduk et al.; licensee Beilstein-Institut.

License and terms: see end of document.

\begin{abstract}
In this work we present an in-depth study of the how the composition of poly(3-hexylthiophene) (P3HT):[6,6]-phenyl- $\mathrm{C}_{61}$-butyric acid methyl ester (PCBM) blend films influences their phase transitions using variable-temperature spectroscopic ellipsometry. We demonstrate that this non-destructive method is a very sensitive optical technique to investigate the phase transitions and to determine the glass transition temperatures and melting crystallization points of the P3HT:PCBM blend films. By analyzing the influence of the temperature $T$ on the raw ellipsometric data, we have identified a high sensitivity of the ellipsometric angle $\Delta$ at a wavelength of $280 \mathrm{~nm}$ to temperature changes. Characteristic temperatures determined from the slope changes of the $\Delta(T)$ plot appeared to be very good guess values for the phase transition temperatures.
\end{abstract}

\section{Introduction}

The organic semiconductor poly(3-hexylthiophene) (P3HT) and the fullerene derivative [6,6]-phenyl- $\mathrm{C}_{61}$-butyric acid methyl ester (PCBM) are extensively studied organic materials because of their important practical applications in organic electronics, especially in organic photovoltaic devices (OPV devices) [1-3]. Their properties are widely reported in literature [4-12]. Usually the OPV devices are constructed as sandwich structures with active layers located between cathode and anode. The most extensively studied and characterized OPV devices are bulk solar cells, with the donor P3HT and the acceptor PCBM. Such solar cells can be fabricated from mixed P3HT and PCBM solutions deposited on transparent electrodes by spin-coating $[13,14]$. Besides, bulk solar cells based on P3HT and PCBM blends became the benchmark for comparisons with maximum values of reported power conversion efficiency ranging from $5 \%$ to $8 \%$. However, frequently reported mean values of OPV device efficiencies range from $3 \%$ to $5 \%$. An important factor which influences OPV devices performance is the morphology of their active layers, e.g., the spatial order of the polymer backbone in the devices based on polymer-fullerene layers. For this reason, 
the morphology of the active layer in OPV devices has been intensively studied $[15,16]$. In general, it can be modified by the blend composition [17], the type of solvent used in processing [18], the use of chemical additives to the solution [19], and diverse post-deposition treatments, e.g., heat treatment [20,21]. One large branch of studies on OPV devices based on thin films of polymer:fullerene blend active layers deals with the optimization of their power conversion efficiency by applying thermal annealing [8]. Remarkably, it has been proven that the power conversion efficiency of OPV devices can be also optimized using thermal treatment related to the phase transition temperature. For instance, Pearson et al. [22] demonstrated that the most efficient devices were heated above the upper apparent glass transition temperature $\left(T_{\mathrm{g}}\right)$ of P3HT:PCBM blends. They also related the value of the optimum annealing temperature for a given sample to their content of PCBM. What is important, these results were confirmed using two different experimental methods that allow for the determination of $T_{\mathrm{g}}$. Namely, dynamic mechanical thermal analysis (DMTA) and spectroscopic ellipsometry (SE). Moreover, with both techniques they detected two $T_{\mathrm{g}}$ transitions in thin films of P3HT:PCBM for a certain range of PCBM content. SE is a non-destructive and very sensitive technique for thin films investigations [23-25]. Generally, ellipsometry measures a change in the polarization of reflected light. The change of light polarization is described by ellipsometric angles $\Psi$ and $\Delta$. Typically, ellipsometric investigations allow one to determine optical parameters, i.e., the refractive index $n$ and the extinction coefficient $k$, or equivalently the complex dielectric function $\varepsilon \equiv(n+\mathrm{i} k)^{2} \equiv \varepsilon_{1}+\mathrm{i} \varepsilon_{2}$, as well as the film thickness $d$. Variable-temperature spectroscopic ellipsometry additionally explores dependence of these quantities on the temperature $T$. This technique is sensitive to phase transitions because they are accompanied by a change in the volume expansion coefficient, which can be detected as change in the slope of $d(T)$ plots [26]. Variable-temperature spectroscopic ellipsometry has been applied to study thin films of polymers such as polystyrene (PS) [27-31], poly( $\alpha$-methylstyrene) [32], poly(methyl methacrylate) (PMMA) [33,34] and polyester [35], but also conjugated polymers such as polyfluorenes [36-38], quinoxaline and carbazole-based copolymers [39,40] and conjugated polymer:fullerene blends [23,41,42]. Frequently, the identification of the phase transition temperatures can be performed using the raw ellipsometric data $[28,41,43]$. However, almost always such an approach is verified for a particular material by an appropriate analysis of $d(T)$ [22]. For example, Müller et al. [26] revealed the $T_{\mathrm{g}}$ profile of thin polymer films in depth and noticed that $T_{\mathrm{g}}$ can be detected directly using $\tan \Psi$. Also, Grohens et al. [44] compared the temperature dependence of the thickness and refractive index with $\cos \Delta(T)$. In this work, we present an in-depth study of the influence of the composition of P3HT:PCBM blend films on

their phase transitions using variable-temperature spectroscopic ellipsometry. We demonstrate that this non-destructive method is a very sensitive optical technique to investigate the phase transitions and to determine the glass temperatures and melting crystallization points for the P3HT:PCBM blend films. By analyzing the influence of the temperature on the raw ellipsometric data, we have identified the high sensitivity of the ellipsometric angle $\Delta$ at $280 \mathrm{~nm}$ to the temperature changes. By comparing the temperature dependence of the film thickness with the corresponding dependence of $\tan \Psi(850 \mathrm{~nm})$ and $\Delta$ $(280 \mathrm{~nm})$, we show that raw data of $\Delta$ at $280 \mathrm{~nm}$ are most convenient to determine the phase diagram of P3HT:PCBM blend films.

\section{Experimental}

Materials we have used are $95.7 \mathrm{wt} \%$ purity regioregular poly(3-hexylthiophene-2,5-diyl) M102-P3HT (Figure 1a) and above $99 \mathrm{wt} \%$ purity $[6,6]$-phenyl- $\mathrm{C}_{61}$-butyric acid methyl ester M111-PCBM (Figure 1b), supplied by Ossila.

a)

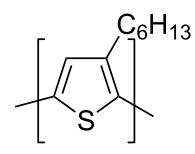

Figure 1: Structures of (a) P3HT and (b) PCBM.

Solutions of P3HT and PCBM in chlorobenzene were stirred for $24 \mathrm{~h}$ at a temperature of $60{ }^{\circ} \mathrm{C}$. After that, the solutions were mixed together with different ratios of P3HT to PCBM from pure P3HT to pure PCBM, keeping a constant weight concentration of $20 \mathrm{mg} / \mathrm{mL}$. The individual weight concentrations of ingredients were selected as indicated in Table 1. Thin films of P3HT, PCBM and P3HT:PCBM blend were deposited on opaque and transparent microscopic glasses through spincoating at $2000 \mathrm{rpm}$. All samples were kept at $60^{\circ} \mathrm{C}$ in the laboratory drier.

Table 1: Nominal composition of studied P3HT:PCBM blend films.
\begin{tabular}{llllllllll} 
sample & 1 & 2 & 3 & 4 & 5 & 6 & 7 & 8 \\
\hline P3HT [\%] & 100 & 85 & 70 & 60 & 50 & 35 & 20 & 0 \\
PCBM [\%] & 0 & 15 & 30 & 40 & 50 & 65 & 80 & 100
\end{tabular}

Variable-temperature spectroscopic ellipsometry measurements have been performed using a SENTECH SE850E spectroscopic 
ellipsometer working in the spectral range of 240-2500 nm under the Spectra Ray 3 Software. The spectrometer is additionally equipped with a variable-temperature cell operating at low pressures and the temperature controller INSTEC mK1000. The cell construction allows for ellipsometric measurements at an incidence angle of $70^{\circ}$ with a very precise temperature control through an electric heater and a liquid-nitrogen circuit.

We have applied the following measurement protocol for our variable-temperature spectroscopic ellipsometry investigations. Every sample was annealed at $250{ }^{\circ} \mathrm{C}$ for 2 min and quickly cooled down to $-10{ }^{\circ} \mathrm{C}$ over a period of $3 \mathrm{~min}$. It is important to note that thermal stability of $\mathrm{P} 3 \mathrm{HT}$ and PCBM is high and their thermal degradation occurs only above $380^{\circ} \mathrm{C}$ [45]. Then, ellipsometric measurements have been performed, during a heating cycle with a heating rate of $2{ }^{\circ} \mathrm{C} / \mathrm{min}$, in the UV-vis-NIR range and with $10 \mathrm{~s}$ intervals. All the measurements were performed under a pressure of $10^{-1}$ Torr.

The absorption measurements have been carried out at room temperature using a two-beam UV-vis-NIR spectrophotometer JASCO V-570.

Additionally, we have determined the glass transition temperatures using a DSC 2920 apparatus (TA Instruments, Newcastle, DE, USA), with aluminum sample pans. Thermal characteristics of the samples were obtained under nitrogen atmosphere (gas flow $=50 \mathrm{~mL} / \mathrm{min}$ ). The instrument was calibrated with high-purity indium and gallium standards. DSC measurements have been performed on powder materials (P3HT and PCBM) and on P3HT:PCBM (1:1) blend, which was scrapped off a glass substrate (thick layer, spin-coated with a spinning rate of $500 \mathrm{rpm})$.

\section{Results and Discussion}

In Figure 2, the absorbance of thin films of P3HT, PCBM and P3HT:PCBM (1:1) is shown. It can be readily observed, that the absorbance in all these films disappears for wavelengths longer than $\lambda=750 \mathrm{~nm}$. For this reason, in ellipsometric studies we can describe the studied films within the Cauchy optical model and determine their thickness as a function of the temperature at long wavelengths.

The Cauchy optical model parametrizes the spectral dependence of the refractive index $n$ and the extinction coefficient $k$ on the wavelength $\lambda$ by the following relations:

$$
n(\lambda, T)=n_{0}(T)+C_{0} \frac{n_{1}(T)}{\lambda^{2}}+C_{1} \frac{n_{2}(T)}{\lambda^{4}},
$$

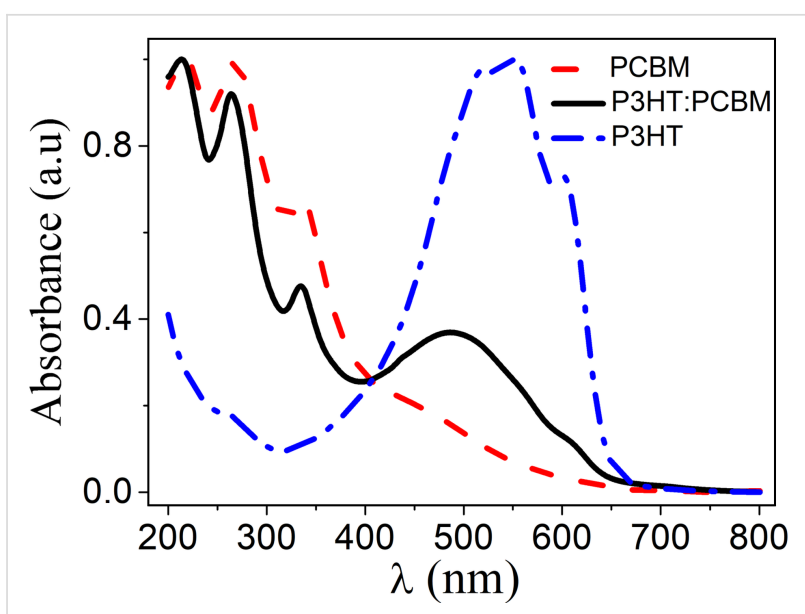

Figure 2: UV-vis absorbance spectra of $\mathrm{P} 3 \mathrm{HT}, \mathrm{PCBM}$ and P3HT:PCBM (1:1) thin films.

$$
k(\lambda, T)=k_{0}(T)+C_{0} \frac{k_{1}(T)}{\lambda^{2}}+C_{1} \frac{k_{2}(T)}{\lambda^{4}},
$$

where the temperature-dependent parameters $n_{i}$ and $k_{i}$, with $i=0,1$ and 2 , are the model (fitting) parameters and the coefficients $C_{0}$ and $C_{1}$ are the numerical constants. It follows from the relations presented above, that at sufficiently long wavelengths both $n$ and $k$ become only temperature-dependent. Additionally, by taking into account the results presented in Figure 2, we can safely assume that $k_{0}(T)=0$ for $\lambda>750 \mathrm{~nm}$.

In Figure 3, thicknesses $d$ as a function of the temperature for P3HT, PCBM and P3HT:PCBM (1:1) blend films are shown. At each measured temperature $T$ the thickness was determined by fitting the Cauchy optical model to the experimental data using the SpectraRay 3 software from SENTECH Instruments.

For comparison, we have also presented in Figure 3 the corresponding temperature dependence of $\tan \Psi$ taken at $\lambda=850 \mathrm{~nm}$. Both plots, $d(T)$ and $\tan \Psi(T)$, are pairwise almost identical. This is because those materials are transparent at $\lambda>750 \mathrm{~nm}$ and their refractive indexes are weakly dependent on $T$ in this spectral range. Regarding P3HT in Figure 3a, we can detect from a change in slope in the plots of $d(T)$ and $\tan \Psi(T)$ three characteristic temperatures at around 10,50 and $126^{\circ} \mathrm{C}$. In Figure $3 \mathrm{~b}$, for PCBM, two characteristic temperatures are seen at 110 and $128^{\circ} \mathrm{C}$ in the $d(T)$ plot and at 111 and $126^{\circ} \mathrm{C}$ in the $\tan \Psi(T)$ plot. Significantly more characteristic temperatures can be detected in Figure 3c, for the P3HT:PCBM (1:1) film. The values are about $22,44,80,112,130$ and $153{ }^{\circ} \mathrm{C}$ in the $d(T)$ plot and about $19,45,80,112,130$ and $150^{\circ} \mathrm{C}$ in the $\tan \Psi(T)$ plot. It is worthy of note, that the difference between corresponding characteristic temperatures detected in $d(T)$ and 

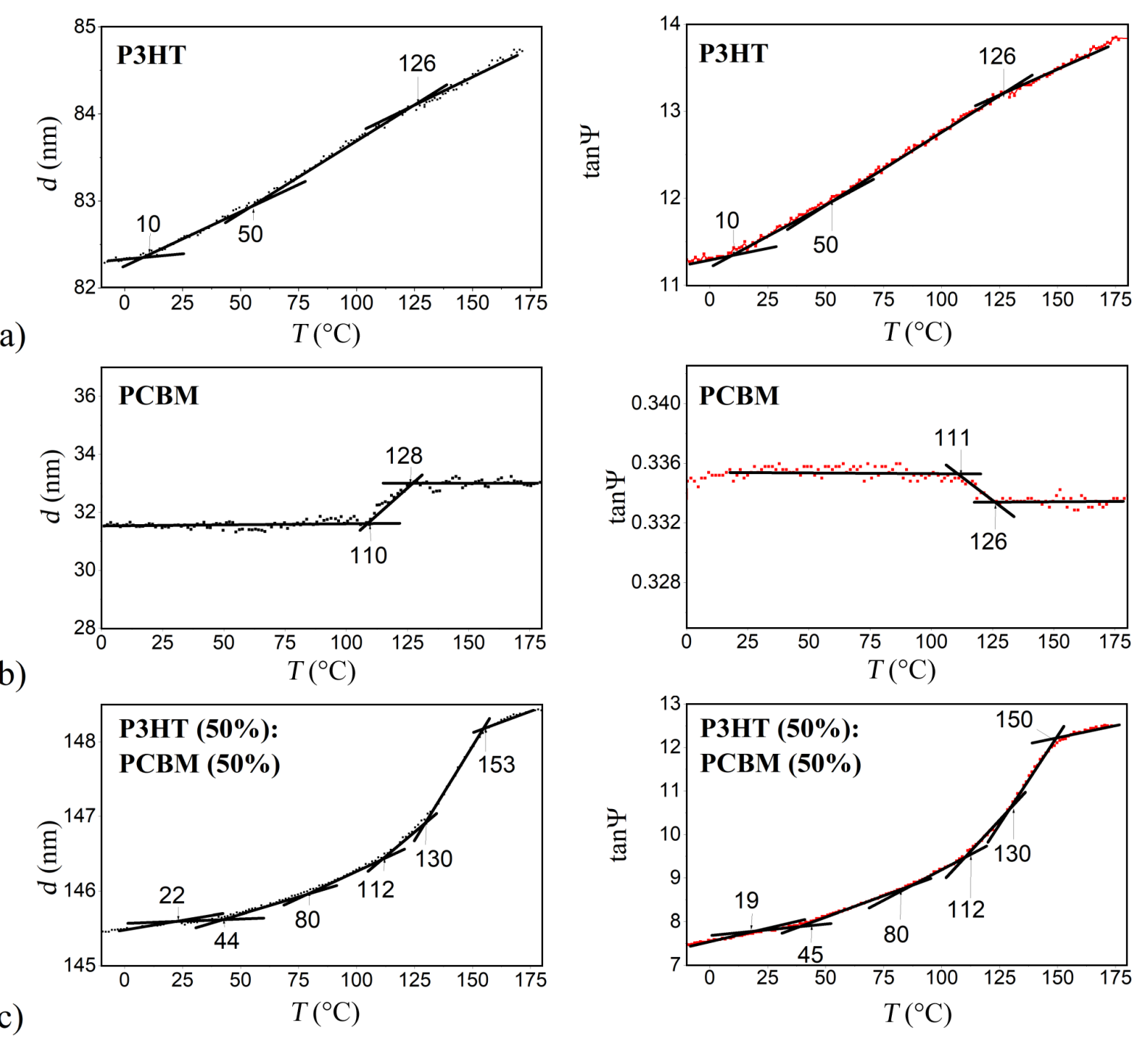

Figure 3: Thickness $d$ and $\tan \Psi$ as functions of the temperature for (a) P3HT, (b) PCBM and (c) P3HT:PCBM (1:1) thin films.

$\tan \Psi(T)$ plots do not excess $3{ }^{\circ} \mathrm{C}$. Nevertheless, those results revealed also difficulties in a certain detection of the characteristic temperatures, at least in a few cases, e.g., those of 50 and $80^{\circ} \mathrm{C}$. For this reason, we have searched for more unambiguous indicators of thermal transitions. By comparing the temperature dependence of raw ellipsometric data of the P3HT:PCBM blend films with different PCBM content, we have found that $\Delta(T)$ taken at $\lambda=280 \mathrm{~nm}$ is the most convenient quantity for this purpose. Mainly because PCBM has a strong absorption band with the maximum located at around $260 \mathrm{~nm}$.

In Figure 4, $\Delta$ at $\lambda=280 \mathrm{~nm}$ as a function of the temperature is shown for the studied P3HT:PCBM blend films. The values of characteristic temperatures found in $d(T)$ plots in Figure 3, fully correspond to the values detected in Figure 4, for P3HT, PCBM and P3HT:PCBM (1:1) films. We have verified that for all studied PCBM compositions the characteristic temperatures indicated in Figure 4, have been recovered on corresponding plots of $d(T)$ and $\tan \Psi(T)$, which are not shown here for clarity of presentation. In order to facilitate identification of the origin of all those thermal transitions we have performed DSC studies on powder materials (P3HT and PCBM) and on the P3HT:PCBM (1:1) film scrapped off a glass substrate. The results of the calorimetric measurements with a constant heating rate of $20^{\circ} \mathrm{C} / \mathrm{min}$ are shown in Figure 5.

A modest number of characteristic temperatures have been detected in Figure 5. Regarding P3HT, $T_{\mathrm{g}}$ is located at $10.30{ }^{\circ} \mathrm{C}$ and the beginning of the melting endotherm at around $215^{\circ} \mathrm{C}$ is also visible. The temperature scan for the P3HT:PCBM sample, heated from -50 to $250{ }^{\circ} \mathrm{C}$, reveals only the glass transition at $48.39{ }^{\circ} \mathrm{C}$. The results for PCBM show $T_{\mathrm{g}}$ at $124.03{ }^{\circ} \mathrm{C}$ and two 

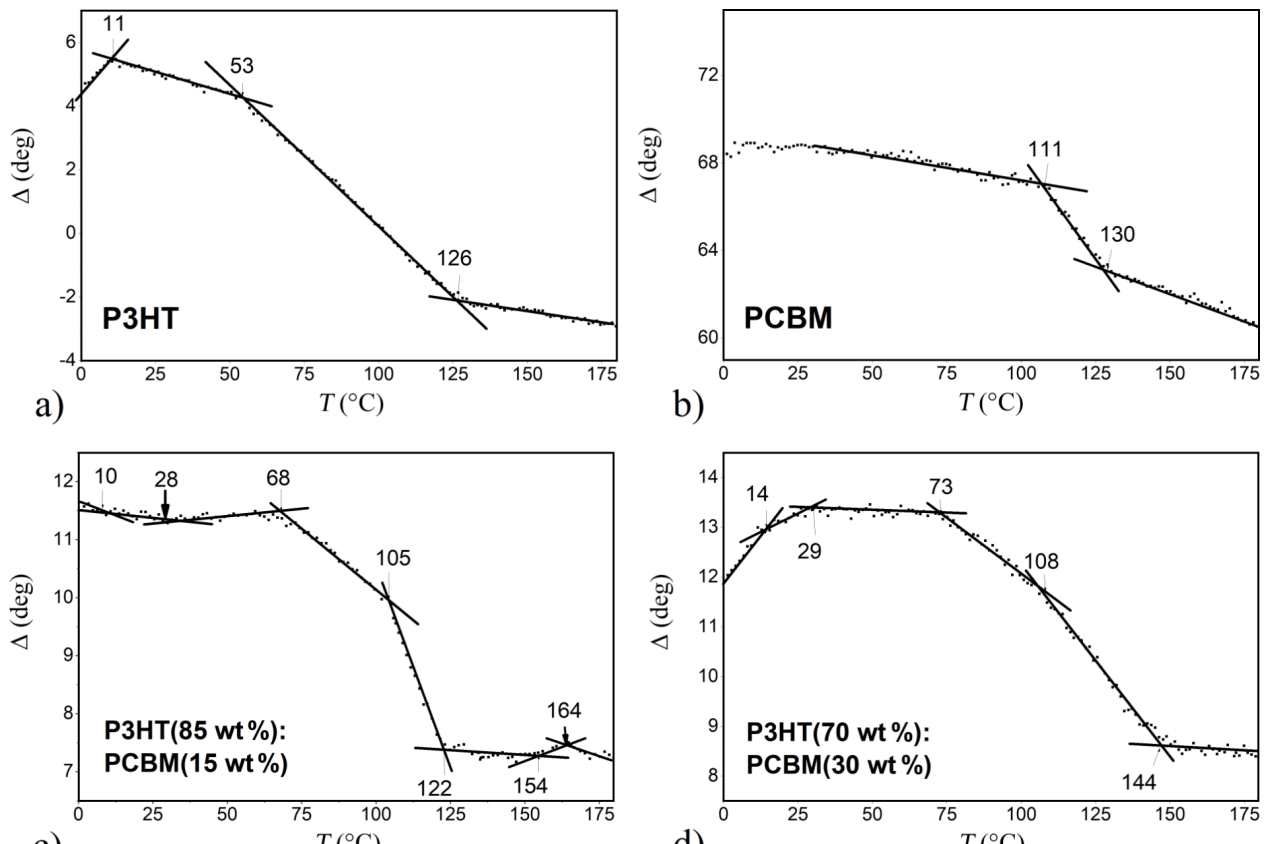

c)

d)
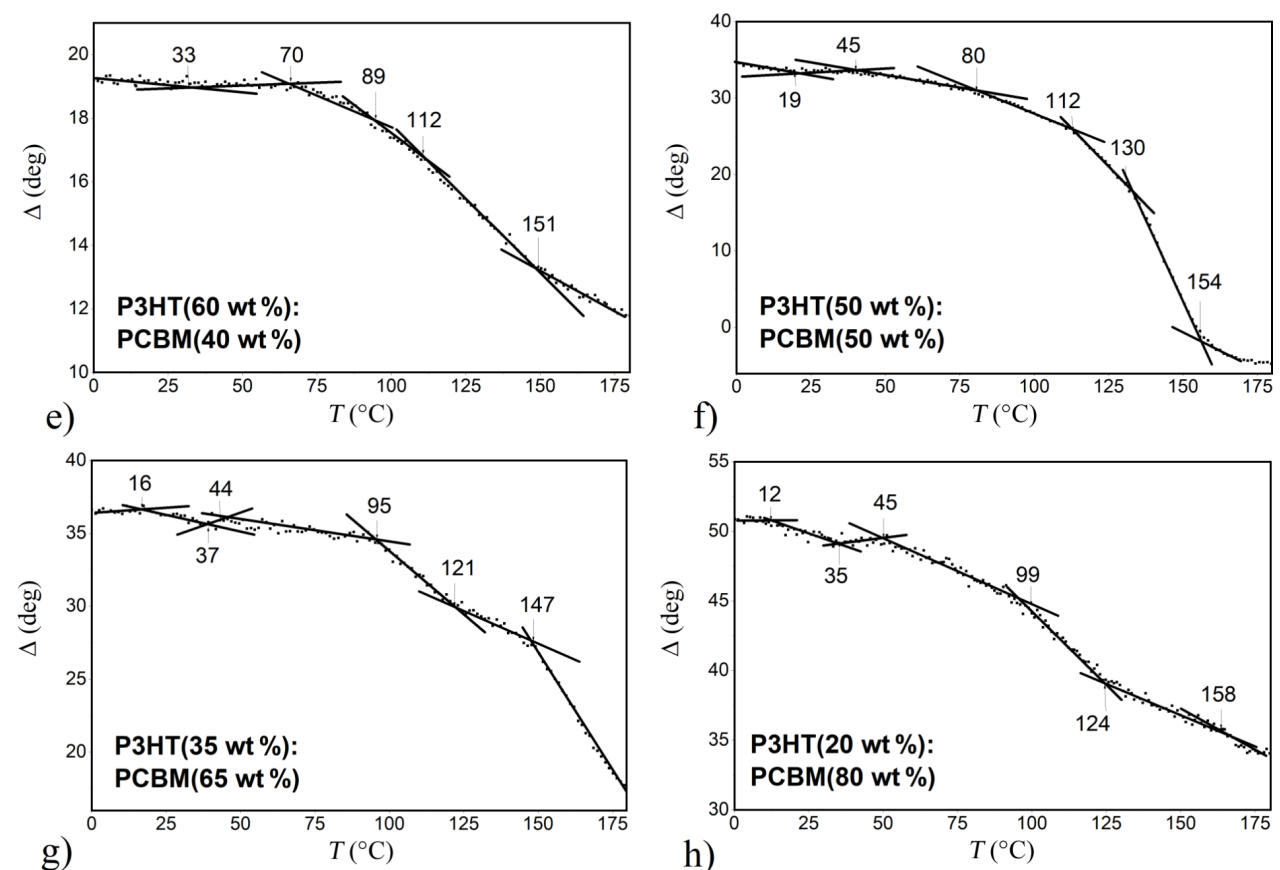

Figure 4: $\Delta$ at $280 \mathrm{~nm}$ as a function of temperature for P3HT:PCBM blend films with different polymer contents: a) P3HT, b) PCBM, c) 15 , d) 30 , e) 40 , f) 50, g) 65 and h) $80 \mathrm{wt} \%$ PCBM.

peaks of exothermic crystallization processes with maxima at $191.08{ }^{\circ} \mathrm{C}$ and at $265.44{ }^{\circ} \mathrm{C}$. Also, the subsequent melting endotherm with a sharp minimum at $284.53{ }^{\circ} \mathrm{C}$ is visible. Having determined phase transitions from the DSC measurements, we return to our ellipsometric results. We can now identify in Figure 3 that glass transitions occurred in the P3HT, P3HT:PCBM (1:1) and PCBM films at temperatures of 10, 21 and $110{ }^{\circ} \mathrm{C}$, respectively. The glass transition temperatures found by DSC were slightly higher than the corresponding temperatures determined with ellipsometry. This can be ascribed to different heating rates used in both experimental methods, and/ or to the influence of films thickness on their phase behavior $[22,46]$. However, given that in our studies the thickness of the films varied over a wide range, between $30 \mathrm{~nm}(83 \mathrm{~nm})$ and 


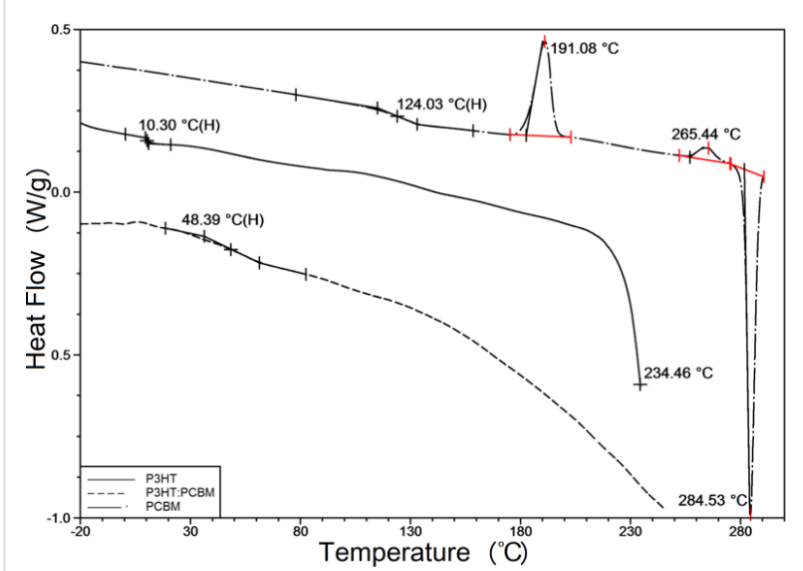

Figure 5: DSC plots with a heating rate of $20^{\circ} \mathrm{C} / \mathrm{min}$ for $\mathrm{P} 3 \mathrm{HT}, \mathrm{PCBM}$ and P3HT:PCBM (1:1), recorded with powder materials (P3HT and PCBM) and with the P3HT:PCBM (1:1) film scrapped off a glass substrate.

$150 \mathrm{~nm}$, the latter cause seems to be more likely. In Figure 6, all characteristic temperatures for P3HT/PCBM blend films with different PCBM content, found in Figure 4 are shown.

This phase diagram can be rationalized as follows: We draw on it three horizontal straight lines passing through the glass transition temperatures of P3HT, P3HT:PCBM (1:1) and PCBM films. Now, it can be clearly seen that the glass transitions of pure materials are present even in our P3HT:PCBM blend films. This is consistent with the coexistence of the mixture as well as pure material phases in our samples. The glass transition temperatures, drawn with symbols marked as $T_{\text {gBLEND }}$, increases with percentage $\mathrm{PCBM}$ content and can be ascribed to P3HT:PCBM mixtures. Their values are in good agreement with those reported in literature for P3HT:PCBM blend $[45,47,48]$. Transitions marked as $T_{\mathrm{c} 1}$, lying below $T_{\mathrm{gPCBM}}$ should be ascribed to thermal transitions connected with the crystallization of $\mathrm{P} 3 \mathrm{HT}$, because this thermal transition is also present in P3HT. The identification of remaining transitions is ambiguous due to complex morphology of our P3HT:PCBM blend films. Nevertheless, it should be noted that the phase diagram determined by us is in a good agreement with that reported by Hopkinson et al. [47] obtained by dynamic mechanical thermal analysis.

\section{Conclusion}

In this work we have presented an in-depth study of the influence of the composition of poly(3-hexylthiophene) (P3HT):[6,6]-phenyl- $\mathrm{C}_{61}$-butyric acid methyl ester (PCBM) blend films on their phase transitions using variable-temperature spectroscopic ellipsometry. We have investigated thin films of P3HT:PCBM blends deposited by spin-coating. Our studies included optical absorption spectroscopy, variable-temperature spectroscopic ellipsometry and differential scanning calorimetry. Based on the absorption spectra we determined the beginning of the spectral transparency region of our samples at $\lambda=750 \mathrm{~nm}$. This allowed us to apply the Cauchy optical model to ellipsometric data analysis in the transparency region and determine the samples thickness $d$ as a function of temperature $T$. The obtained $d(T)$ plots were the base for the determination of phase diagrams. By analyzing the influence of temperature on the raw ellipsometric data, we have identified a high sensitivity

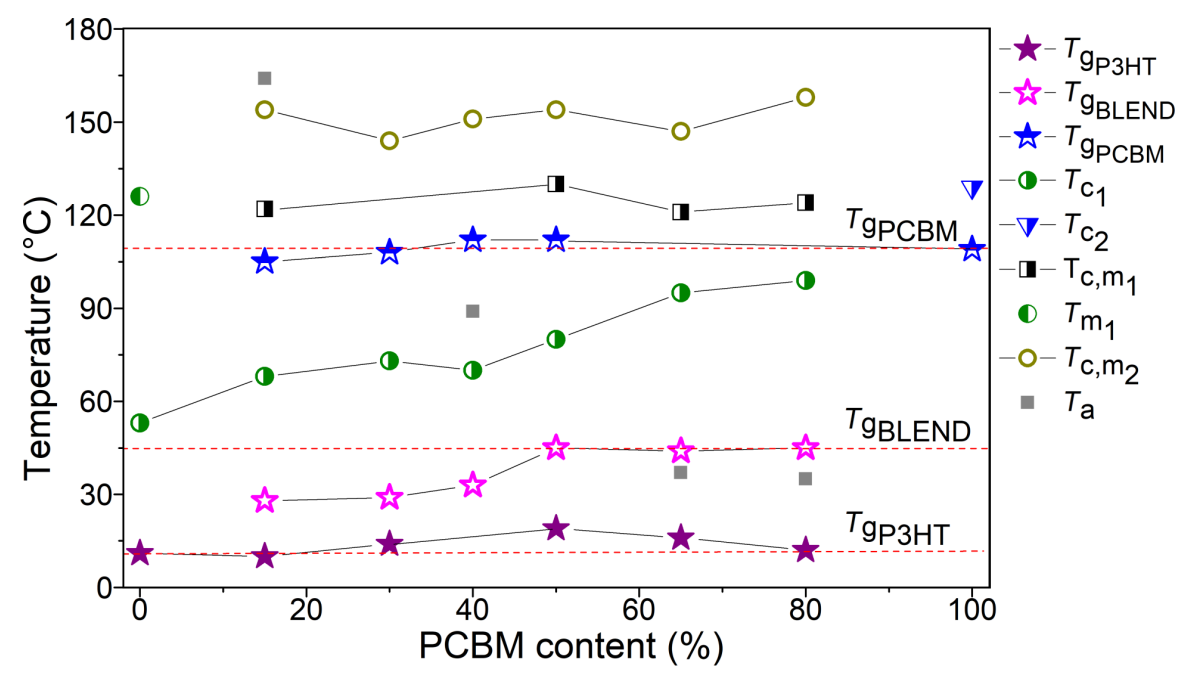

Figure 6: Phase diagram of P3HT:PCBM blends films. Symbols marked as $T_{\mathrm{gP} 3 \mathrm{HT}}, T_{\mathrm{gBLEND}}$ and $T_{\mathrm{gPCBM}}$ denote the glass transitions of P3HT, P3HT:PCBM blend and PCBM phases. $T_{\mathrm{c} 1}, T_{\mathrm{c} 2}, T_{\mathrm{c}, \mathrm{m} 1}, T_{\mathrm{m} 1}$ and $T_{\mathrm{c}, \mathrm{m} 2}$ are phase transitions related the P3HT crystallization, the PCBM cold crystallization, the melting of $\mathrm{P} 3 \mathrm{HT}$ crystallization and/or crystallization of PCBM, melting of P3HT crystallization as well as the additional crystallization of PCBM, respectively. Symbols marked as $T_{\mathrm{a}}$ denote additional phase transitions. 
of the ellipsometric angle $\Delta$ at a wavelength of $280 \mathrm{~nm}$ to temperature changes. Characteristic temperatures determined from the slope changes of the $\Delta(T)$ plot appeared to be very good guess values for the phase transition temperatures. We have identified characteristic temperatures originating from glass transitions and cold crystallization or melting of crystallization phases of P3HT, P3HT:PCBM mixture and PCBM. The clear advantages of this method are the possibility to directly monitor the phase behavior of P3HT:PCBM thin layers and to accurately estimate their characteristic temperatures. In addition, this method allows one to omit a time-consuming theoretical analysis of ellipsometric data and limits the measurements to a very narrow spectral range. This, in turn, complements the already known advantages of variable-temperature ellipsometry, such as less sensitivity to sample imperfections and very high sensitivity to sample thickness.

\section{Acknowledgements}

This work has been supported by the NCN grant (Poland) No. UMO-2013/09/B/ST8/01629.

\section{References}

1. Adam, G.; Munkhbat, B.; Denk, P.; Ulbricht, C.; Hrelescu, C.; Scharber, M. C. Front. Mater. 2016, 3, 39. doi:10.3389/fmats.2016.00039

2. Tzounis, L.; Gravalidis, C.; Papamichail, A.; Logothetidis, S. Mater. Today: Proc. 2016, 3, 832-839. doi:10.1016/j.matpr.2016.02.016

3. Holliday, S.; Ashraf, R. S.; Wadsworth, A.; Baran, D.; Yousaf, S. A.; Nielsen, C. B.; Tan, C.-H.; Dimitrov, S. D.; Shang, Z.; Gasparini, N.; Alamoudi, M.; Laquai, F.; Brabec, C. J.; Salle, A.; Durrant, J. R.; Mc Culloch, I. Nat. Commun. 2016, 7, 11585. doi:10.1038/ncomms11585

4. Ludwigs, S., Ed. P3HT Revisited - From Molecular Scale to Solar Cell Devices; Springer, 2014. doi:10.1007/978-3-662-45145-8

5. Bagienski, W. R. Temperature Dependence of P3HT/PCBM Organic Solar Cell Device Performance. Ph.D. Thesis, University of Virginia, Charlottesville, VA, USA, 2009.

6. Freisinger, B. Investigation of P3HT PCBM Particle-based Solar Cells. Ph.D. Thesis, Johannes Gutenberg University, Mainz, Germany, 2013.

7. Mayer, A. C.; Scully, S. R.; Hardin, B. E.; Rowell, M. W.; Mc Gehee, M. D. Mater. Today 2007, 10, 28-33. doi:10.1016/S1369-7021(07)70276-6

8. Yu, J.; Zheng, Y.; Huang, J. Polymers (Basel, Switz.) 2014, 6, 2473-2509. doi:10.3390/polym6092473

9. Swart, H. C.; Ntwaeaborwa, O. M.; Mbule, P. S.; Dhlamini, M. S.; Mothudi, B. B. J. Mater. Sci. Eng. B 2015, 5, 12-35. doi:10.17265/2161-6221/2015.1-2.002

10. Vanlaeke, P.; Swinnen, A.; Haeldermans, I.; Vanhoyland, G.; Aernouts, T.; Cheyns, D.; Deibel, C.; D’Haen, J.; Heremans, P.; Poortmans, J.; Manca, J. V. Sol. Energy Mater. Sol. Cells 2006, 90, 2150-2158. doi:10.1016/j.solmat.2006.02.010

11. Shen, Y.; Li, K.; Majumdar, N.; Campbell, J. C.; Gupta, M. C. Sol. Energy Mater. Sol. Cells 2011, 95, 2314-2317. doi:10.1016/j.solmat.2011.03.046
12. Dang, M. T.; Wantz, G.; Bejbouji, H.; Urien, M.; Dautel, O. J.; Vignau, L.; Hirsch, L. Sol. Energy Mater. Sol. Cells 2011, 95, 3408-3418. doi:10.1016/j.solmat.2011.07.039

13. Extrand, C. W. Polym. Eng. Sci. 1994, 34, 390-394. doi:10.1002/pen.760340503

14. Norrman, K.; Ghanbari-Siahkali, A.; Larsen, N. B. Annu. Rep. Prog. Chem., Sect. C: Phys. Chem. 2005, 101, 174-201. doi:10.1039/b408857n

15. Rumer, J. W.; Mc Culloch, I. Mater. Today 2015, 18, 425-435. doi:10.1016/j.mattod.2015.04.001

16. Chang, L.; Jacobs, I. E.; Augustin, M. P.; Moulé, A. J. Org. Electron. 2013, 14, 2431-2443. doi:10.1016/j.orgel.2013.06.016

17. Wright, M.; Lin, R.; Tayebjee, M. J. Y.; Conibeer, G. Sol. RRL 2017, 1, 1700035. doi:10.1002/solr.201700035

18. Morana, M.; Koers, P.; Waldauf, C.; Koppe, M.; Muehlbacher, D.; Denk, P.; Scharber, M.; Waller, D.; Brabec, C. Adv. Funct. Mater. 2007, 17, 3274-3283. doi:10.1002/adfm.200700124

19. Kim, W.; Kim, J. K.; Kim, E.; Ahn, T. K.; Wang, D. H.; J. Park, J. H. J. Phys. Chem. C 2015, 119, 5954-5961. doi:10.1021/jp510996w

20. Park, S.; Seo, Y.-S.; Shin, W. S.; Moon, S.-J.; Hwang, J. Sci. Rep. 2016, 6, 22604. doi:10.1038/srep22604

21. Lee, C.-C.; Liu, S.-W.; Cheng, C.-W.; Su, W.-C.; Chou, C. C.; Lin, C.-F.; Chen, C.-T. Int. J. Photoenergy 2013, 2013, 585196. doi:10.1155/2013/585196

22. Pearson, A. J.; Wang, T.; Jones, R. A. L.; Lidzey, D. G.; Staniec, P. A.; Hopkinson, P. E.; Donald, A. M. Macromolecules 2012, 45, 1499-1508. doi:10.1021/ma202063k

23. Campoy-Quiles, M.; Alonso, M. I.; Bradley, D. D. C.; Richter, L. J. Adv. Funct. Mater. 2014, 24, 2116-2134. doi:10.1002/adfm.201303060

24. Ng, A.; Liu, X.; To, C. H.; Djurišić, A. B.; Zapien, J. A.; Chan, W. K. ACS Appl. Mater. Interfaces 2013, 5, 4247-4259. doi:10.1021/am4004232

25. Kim, H.; So, W.-W.; Moon, S.-J. J. Korean Phys. Soc. 2006, 48, $441-445$

26. Müller, C.; Andersson, L. M.; Peña-Rodrguez, O.; Garriga, M.; Inganäs, O.; Campoy-Quiles, M. Macromolecules 2013, 46, 7325-7331. doi:10.1021/ma400871u

27. Beaucage, G.; Composto, R.; Stein, R. S. J. Polym. Sci., Part B: Polym. Phys. 1993, 31, 319-326. doi:10.1002/polb.1993.090310310

28. Keddie, J. L.; Jone, R. A. L.; Cory, R. A. Europhys. Lett. 1994, 27, 59-64. doi:10.1209/0295-5075/27/1/011

29. Dalnoki-Veress, K.; Forrest, J. A.; Murray, C.; Gigault, C.; Dutcher, J. R. Phys. Rev. E 2001, 63, 031801. doi:10.1103/PhysRevE.63.031801

30. Singh, L.; Ludovice, P. J.; Henderson, C. L. Thin Solid Films 2004, 449, 231-241. doi:10.1016/S0040-6090(03)01353-1

31. Kawana, S.; Jones, R. A. L. Phys. Rev. E 2001, 63, 021501. doi:10.1103/PhysRevE.63.021501

32. Kim, J. H.; Jang, J.; Zin, W.-C. Langmuir 2000, 16, 4064-4067. doi:10.1021/la991618t

33. Sharp, J. S.; Forrest, J. A. Phys. Rev. E 2003, 67, 031805. doi:10.1103/PhysRevE.67.031805

34. Erber, M.; Tress, M.; Mapesa, E. U.; Serghei, A.; Eichhorn, K.-J.; Voit, B.; Kremer, F. Macromolecules 2010, 43, 7729-7733. doi:10.1021/ma100912r

35. Erber, M.; Khalyavina, A.; Eichhorn, K.-J.; Voit, B. I. Polymer 2010, 51, 129-135. doi:10.1016/j.polymer.2009.11.032

36. Campoy-Quiles, M.; Etchegoin, P. G.; Bradley, D. D. C. Synth. Met. 2005, 155, 279-282. doi:10.1016/j.synthmet.2005.01.031 
37. Sims, M.; Zheng, K.; Campoy Quiles, M.; Xia, R.; Stavrinou, P. N.; Bradley, D. D. C.; Etchegoin, P. J. Phys.: Condens. Matter 2005, 17, 6307. doi:10.1088/0953-8984/17/41/002

38. Campoy-Quiles, M.; Sims, M.; Etchegoin, P. G.; Bradley, D. D. C Macromolecules 2006, 39, 7673-7680. doi:10.1021/ma0605752

39. Kroon, R.; Gehlhaar, R.; Steckler, T. T.; Henriksson, P.; Müller, C.; Bergqvist, J.; Hadipour, A.; Heremans, P.; Andersson, M. R. Sol. Energy Mater. Sol. Cells 2012, 105, 280-286. doi:10.1016/j.solmat.2012.06.029

40. Wang, T.; Pearson, A. J.; Dunbar, A. D. F.; Staniec, P. A.; Watters, D. C.; Coles, D.; Yi, H.; Iraqi, A.; Lidzey, D. G.; Jones, R. A. L. Eur. Phys. J. E 2012, 35, 129. doi:10.1140/epje/i2012-12129-3

41. Müller, C.; Bergqvist, J.; Vandewal, K.; Tvingstedt, K.; Anselmo, A. S.; Magnusson, R.; Alonso, M. I.; Moons, E.; Arwin, H.; Campoy-Quiles, M.; Inganäs, O. J. Mater. Chem. 2011, 21, 10676-10684. doi:10.1039/c1jm11239b

42. Campoy-Quiles, M.; Ferenczi, T.; Agostinelli, T.; Etchegoin, P. G.; Kim, Y.; Anthopoulos, T. D.; Stavrinou, P. N.; Bradley, D. D. C.; Nelson, J. Nat. Mater. 2008, 7, 158-164. doi:10.1038/nmat2102

43. Yamamoto, S.; Tsujii, Y.; Fukuda, T. Macromolecules 2002, 35, 6077-6079. doi:10.1021/ma0255128

44. Grohens, Y.; Brogly, M.; Labbe, C.; David, M.-O.; Schultz, J. Langmuir 1998, 14, 2929-2932. doi:10.1021/la971397w

45. Ngo, T. T.; Nguyen, D. N.; Nguyen, V. T. Adv. Nat. Sci.: Nanosci. Nanotechnol. 2012, 3, 045001. doi:10.1088/2043-6262/3/4/045001

46. Kim, J. H.; Jang, J.; Zin, W.-C. Langmuir 2001, 17, 2703-2710. doi:10.1021/la001125k

47. Hopkinson, P. E.; Staniec, P. A.; Pearson, A. J.; Dunbar, A. D. F.; Wang, T.; Ryan, A. J.; Jones, R. A. L.; Lidzey, D. G.; Donald, A. M. Macromolecules 2011, 44, 2908-2917. doi:10.1021/ma102524a

48. Zhao, J.; Swinnen, A.; Van Assche, G.; Manca, J.; Vanderzande, D.; Van Mele, B. J. Phys. Chem. B 2009, 113, 1587-1591. doi:10.1021/jp804151a

\section{License and Terms}

This is an Open Access article under the terms of the Creative Commons Attribution License (http://creativecommons.org/licenses/by/4.0), which permits unrestricted use, distribution, and reproduction in any medium, provided the original work is properly cited.

The license is subject to the Beilstein Journal of Nanotechnology terms and conditions: (https://www.beilstein-journals.org/bjnano)

The definitive version of this article is the electronic one which can be found at: doi:10.3762/bjnano.9.102 